\title{
Postpartum cultural practices contributing to maternal deaths in Lundazi district- Zambia
}

\author{
Jordan Tembo ${ }^{1}$, Patricia Mambwe ${ }^{2}$ \\ ${ }^{1}$ Kalindawalo General Hospital, Petauke, Zambia \\ ${ }^{2}$ Department of Nursing, School of Health Sciences, Rusangu University, Monze, Zambia
}

\begin{abstract}
The problem of maternal deaths affects all nations. This study explored postpartum cultural practices surrounding deaths associated with post childbirth in Lundazi district Zambia. The study used a cross-sectional study design with a qualitative approach. The study used 30 Small Motherhood Action Group members (SMAGs) as study units. Three Focus Group Discussions were conducted during the month of May 2018. This study found that some postpartum women in Lundazi district- Zambia used dirty, contaminated cloths as sanitary pads. The study also found that women who sustained tears, bruises or lacerations during childbirth treated their childbirth wounds by padding or inserting into their birth canals, herbal medicines prepared under unhygienic conditions. The reality of the existence of unsafe postpartum cultural practices should never be ignored or minimized as this borders on complications and death of women after childbirth. Despite the existence of a vibrant modern health care system, women slide into harmful cultural practices post childbirth which endanger their health and their lives. The cultural practice of inserting traditional herbal medicines prepared under unhygienic conditions into the vagina for treatment of bruises, cuts and lacerations exposes women to large concentrations of harmful micro-organisms placing them in the red zone of developing complicated ascending infection with consequent death in case of delay to access health care services.
\end{abstract}

Key words: Postpartum, puerperal sepsis, maternal death, culture

\section{INTRODUCTION}

$\mathrm{P}$ regnancy is an ultimate journey whose desirable destination is a healthy mother and a healthy baby. Postpartum is a critical period after childbirth. It begins immediately after delivery and continues for approximately six weeks (42days) or until the body has returned to a near pre-pregnant state (Fraser \&Cooper 2009). It is a perilous phase after the delicate completion of the intrapartum. Postpartum is an arc in the history of a woman's life which understandably demands vigilance and conscious skilled care to prevent maternal deaths. Brown (2019) observed that approximately $60 \%$ of maternal deaths occur during the postpartum period. Brown (2019) provides an insightful amplification. He asserts that in fact, women are more likely to die of pregnancy-related conditions in the weeks following birth than during pregnancy or intrapartum (Brown, 2019).

The World Health Organization (2016) identified postpartum haemorrhage, puerperal sepsis and hypertensive disorders as a trident leading causes of maternal deaths during the postpartum period. Puerperal sepsis is defined as the infection of the genital tract occurring at any time between the onset of rupture of membranes, labour and the $42^{\text {nd }}$ day postpartum (Fraser and Cooper 2009).

Puerperal infections include puerperal sepsis but also all extra-genital infections and incidental infections related to labour, delivery and puerperium (Ricci, 2013). Indigenous practices during the postpartum period have been attributed to puerperal infections with eventual postpartum maternal complications and death.

Hyder and Morrow (2005), argue that people around the world have cultural beliefs and practices related to health, pregnancy and childbirth that stem from cultural forces and individual experiences and perceptions. Culture refers to society and its way of life (Lebrón, 2013). It is defined as a set of values or a cluster of learned practices which people of a particular society share (Lebrón, 2013).

Pregnancy, childbirth and after childbirth are an important transitional period in a woman's life, and because of this characteristic, it has been the source of many cultural beliefs and practices through-out history in every cultural environment (Acıpayaml1, 1974; Gölbaşı \& Eğri, 2010).Other scholars too assent that periods when women are most likely to use traditional beliefs and practices are pregnancy, childbirth and the postpartum period (Kaewsarn, Moyle, \& Creedy, 2003; Abuidhail, 2014).

Globally women still carry out certain traditional practices during and after pregnancy, some of which adversely affect them or their babies (Ayaz \& Efe, 2008). In Zambia, cultural childbirth and post childbirth beliefs and practices continue to exist alongside the modern maternity care system (Maimbolwa et al., 2003). Some of these cultural practices have acted as a loaded gun against women during pregnancy, child birth or postpartum period. Lundazi District, a rural town on the eastern part of Zambia with an estimated population of nearly 450,000 people by 2018 , contributed huge numbers of maternal deaths between 2014 and 2016. In 2014, Lundazi district recorded 24 maternal deaths.

In 2015, the number of maternal deaths dropped slightly to 17 . The following year, the number of maternal deaths rose to 21 (Lundazi District Health Office Information Management System, 2014-2017). Biomedical analysis revealed that some women died during the postpartum period due to suspected infection post childbirth. Without a study on cultural practices 
surrounding the postpartum period, health workers could not be completely in charge of the territory to provide decisive interventions. This study was therefore, conducted to explore cultural postpartum practices in Lundazi- Zambia. The study was conducted during the month of May, 2018.

\section{Theory}

The guiding theory for the study was Symbolic Interactionism. This sociological theory is traced from George Herbert Mead and his student Herbert Blumer (Ritzer, 2008). Symbolic Interactionism views culture as an on-going process created when people interact. For women in Lundazi districtZambia, the social reality of cultural exchange occurs as they interact. Through social interaction between the aged women and the younger women, meanings from the physical and social environment as understood and interpreted by the elderly women are derived (Kennedy, 2020). In the process of social interaction, women in Lundazi district, symbolically communicate meanings to one another thereby influencing one another( Ritzer, 2008) to create, recreate and maintain their culture.

\section{MATERIALS AND METHODS}

To explore postpartum cultural practices in Lundazi districtZambia, the study used a cross-sectional study design and a qualitative descriptive approach. Each Focus Group Discussion session performed, comprised 10 participants in line with the suggestion of Mishra (2016) that a focus group discussion consists of a small group - usually 10 to 12 participants. To ensure Trustworthiness, a total of 3 Focus Group Discussion sessions were conducted. For credibility and dependability the study used participants of both gender because the selection of these units sought to "obtain the broadest range of information and perspectives on the subject of study" (Kuzel, 1992:37). The units included men as participants to potentially offer contrary evidence or views, especially given the need for testing rival explanations (Kuzel 1992: 37-41). The study also used an audio recorder to record the discussion. The recorded information was replayed for clarifications and additions from participants. Study participants recruited for the study were members derived from the Small Motherhood Action Groups (SMAGs). The aim of the SMAGs programme in the remote district of Lundazi in Zambia is to raise awareness about pregnancy and birth-related complications and to reduce critical delays in decision-making at a household level about seeking lifesaving maternal healthcare in health facilities (Ensor et al., 2014). Some of the members of the SMAGs were former Traditional Birth Attendants. $67 \%$ of the participants were females while males constituted $33 \%$. The mean age of the participants was 41 years.

Data collection for the study was accomplished through Focus Group Discussions. Each Focus Group Discussion session was conducted in a spacious room taking 60minutes. A thorough explanation on the purpose of the study, consent, and audio recording was given to participants. After obtaining consent from the participants, the researcher proceeded to collect demographic data. Questions from the Focus Group Discussion guide were read in English by the researcher. Translation into Tumbuka was done by the interpreter. Participants' responses were translated from Tumbuka into English by the interpreter. The responses were written down and later typed and stored as a Microsoft copy. At the end of each session, participants were served with refreshments.

\section{RESULTS}

Question. What does a woman do traditionally after she gives birth?

The purpose of this question was to gain a deeper insight into the postpartum cultural practices and to offer an analysis of risky native practices which put postpartum women in the harm's way of developing maternal complications and consequent death. From the Focus Group Discussion sessions, two themes emerged namely use of unhygienic sanitary cloths and insertion of herbal medicines prepared under unhygienic conditions into the mother's birth canal.

\section{Use of unhygienic sanitary cloths}

Participants reported that after childbirth, in villages of Lundazi district-Zambia, a woman plugged her birth canal with a sanitary cloth for a pad. The purpose of this traditional practice was to absorb the post childbirth discharge. The sanitary cloth ranged from a detached shirt or blouse sleeve to a remnant wrapper (chitenge material) or a piece of blanket. The narrative about the ritualistic piece of a frayed cloth was both fascinating and stunning. Participants narrated that the cloth scrap was not picked from a sterile environment rather it was obtained from a garbage dump pit. A grandmother, a mother or a mother in-law to the woman in post-childbirth confinement, went to a household landfill, dug up the rubbish. Whatever piece of cloth she found lying beneath the pile of waste, was carefully exhumed and offered to a mother so she could insert it into her birth canal for a sanitary pad to soak up the discharge.

Participants explained that this cultural practice was premised on the belief that a scrap fabric from a household garbage dump pit had a higher absorbing property and in case the woman sustained a tear during childbirth, her wounds would heal quickly because it was further believed that the contaminated cloth had superior healing properties.

A participant in the group discussion said:

In the village, when a woman has delivered she is told by elderly traditional birth attendants to fill her leaking private part with a piece of cloth acquired from a rubbish pit. The purpose is to assist absorb the discharge after childbirth. The elderly women believe that a cloth exhumed from a rubbish pit has a high water absorbing property and greater healing properties (Focus Group Discussion 2, Female Participant).

Another participant observed the mortal danger of using unhygienic scrap cloth pads in the following statement: 
The material the woman is expected to use after childbirth should be clean and without dirt. But in the village the normal practice is that a woman uses dirty and contaminated cloth pads. This is not a good practice at all because it introduces germs in a woman's tender and bruised birth canal (Focus Group Discussion 3, Male Participant).

\section{Insertion of traditional herbal medicines in the birth canal}

Participants also narrated that it was a traditional practice for elderly women to make herbal preparations for catalyzing the healing process of a woman with childbirth tears, grazes and lacerations. It was reported during Focus Group Discussions that leaves, stem barks or roots of herbal plants were first harvested. Without having to wash the harvest for fear that it may lose potency if washed, the harvest was pounded in a mortar using a pestle. In the absence of a mortar and a pestle, it was reported that a flat stone was used to crush the harvest into desirable piece-size. The contaminated herbal preparation was given to the mother nursing her post childbirth wounds for her to insert into her delicate, bruised and lacerated vagina.

One participant remarked:

When a woman delivers in the village and if her private part sustains tears or cuts, the elderly women prepare traditional herbs which may be pounded roots, stem barks or leaves. The preparation is used by the woman as a wound dressing agent and treatment. (Focus Group Discussion 1, Female Participant).

A male participant highlighted the dangers of using herbal preparations prepared under unhygienic conditions for treating childbirth wounds.

Though this practice is as old as our culture, the danger is that the traditional herbs prepared under unhygienic conditions can potentially introduce germs on the woman's birth canal. The woman may get sick and perhaps die if her illness gets serious and delays to access treatment on time. (Focus Group Discussion 1, Female participant).

\section{DISCUSSION}

Maternal death reduction requires a vigilant watch and relentless provision of skilled care to women during pregnancy, childbirth and the postpartum period. In many cultures, postpartum women are seen as contaminated, and therefore special hygiene cultural practices are required (Cindy-Lee eta 1., 2007).

Jordanian postpartum mothers wash their genitalia thoroughly with soap and water because they are thought to be temporarily 'polluted' by childbirth (Nahas \& Amasheh, 1999). An unsafe and harmful postpartum cultural practice is a huge fallout in the wide continuum of strict motherhood health care. Maternal death due to puerperal sepsis is a persistent problem across centuries but introduction of aseptic technique and antibiotic led to major reduction in maternal deaths in developed nations (Baker, 2006). Severe puerperal sepsis is a known source of severe maternal complications and death in poor-resourced countries (Khaskheli et al., 2013).

A study conducted in Uganda by Ngozi et al., (2016) found that majority of maternal deaths were related to infection acquired during the postpartum period. This study found that postpartum cultural practices in Lundazi district- Zambia, heighten the risk of postpartum women developing and dying from complications originating from postpartum infections due to the use of unhygienic sanitary cloth pads.

Ali et al., (2007) affirm that unhygienic postpartum cultural practices characterized by the use of unhygienic material for the absorption of postpartum discharge has been reported in several studies. Findings of this study are similar to the findings in an Indian study by Narayan et al., (2001) in which participants reported use of less hygienic "old cloth" for sanitary pads. Shreen (1998) caution that such unhygienic practices during postpartum period introduces virulent microorganisms into the normally-sterile environment of the upper reproductive tract (Shireen, 1998). This is further substantiated by the remarks from one of the participants during the Focus Group Discussion:

While culture needs to be perpetuated, certain components of our culture such as the use of dirty sanitary cloths for pads after childbirth is an extremely dangerous traditional practice that exposes a woman to germs that cause serious illness and death ( Focus Group Discussion 2; Male participant).

This study found that postpartum women in Lundazi district Zambia used herbal preparations to dress and treat childbirth wounds.

Findings of this study are in line with the study conducted in Indonesia, Mozambique, South Africa, Bangkok and Thailand by Hilber et al., (2010) in which it was found that women in all these study sites, used traditional preparations of herbs, leaves, bark to maintain vaginal health and well being. The danger of these herbal preparations is related to unhygienic conditions under which they are prepared. Studies conducted

in the South Asian population and Pakistan reported insertion of herbal medicine preparations inside the vagina or uterus during the postpartum period augmenting transmission of micro-organisms to the upper reproductive tract leading to pelvic inflammatory disease culminating in puerperal sepsis and death (Mathews, 1995; Inhorn, 2003). Sepsis may start from the early postpartum period. Shortly after delivery or during the first days post partum the temperature rises and the patient is seriously ill, sometimes in septic shock with low blood pressure and signs of disseminated intravascular coagulation (Swingler et al 1988).

\section{CONCLUSION}

The reality of the existence of unsafe postpartum cultural practices should never be minimized as this borders on post childbirth complications and death. Despite the existence of a 
vibrant modern health care system, women slide into cultural practices that involve use of contaminated cloths for sanitary pads. In situations of childbirth wounds, women pad or insert traditional herbal medicines into their reproductive tract for treatment. This exposes them to large concentrations of harmful micro-organisms placing them in the red zone of developing complicated ascending infection with consequent death if they delay to access health care services.

\section{RECOMMENDATION}

The study recommends that health workers to step up health promotion messages targeting postpartum women, senior citizens, Traditional Healers, Chiefs, headmen and religious leaders against perpetuating cultural practices that promote postpartum infection.

\section{Tables}

Table1.Demographic characteristics of participants

\begin{tabular}{|c|c|}
\hline Participants' Characteristics & Demographics \\
\hline \multicolumn{2}{|l|}{ Gender } \\
\hline Male & $10(33 \%)$ \\
\hline Female & $20(67 \%)$ \\
\hline Mean age in years for all participants & 41 \\
\hline \multicolumn{2}{|l|}{ Educational Levels } \\
\hline $\begin{array}{c}\text { Primary not } \\
\text { completed, } \mathrm{n}(\%)\end{array}$ & $15(50 \%)$ \\
\hline Primary completed, n(\%) & $5(17 \%)$ \\
\hline Junior not completed n(\%) & $5(17 \%)$ \\
\hline Junior completed n(\%) & $3(10 \%)$ \\
\hline Senior not completed(\%) & $1(3 \%)$ \\
\hline Senior completed(\%) & $1(3 \%)$ \\
\hline \multicolumn{2}{|l|}{ Marital Status } \\
\hline Single & $2(6.7 \%)$ \\
\hline Married & $26(87 \%)$ \\
\hline Widowed & $2(6.7 \%)$ \\
\hline
\end{tabular}

\section{AUTHORS' CONTRIBUTIONS}

JT was responsible for the study conception and design, data collection, and analysis. PM edited the manuscript.

\section{ACKNOWLEDGEMENTS}

The authors are grateful to the Eastern Provincial Health Office and Lundazi District health office team for approving the request to undertake this study. Many thanks go to the participants for their willingness to participate in this study.

\section{REFERENCES}

[1] Abuidhail, J. (2014). Rural Jordanian Mothers' beliefs, knowledge and practices of postnatal care. Quality in Primary Care, 22(6), $285-293$
[2] Acipayamlı, O.,1974, Türkiye'de doğumla ilgili âdet ve inanmaların etnolojik etüdü. Ankara: Sevinç Matbaası;

[3] Ali, T.S. Fikree, F.F. Rahbar, M.H. (2006). Frequency and determinants of vaginal infection in postpartum period: a crosssectional survey from low socioeconomic settlements, Karachi, Pakistan. J Pak Med Assoc 2006 Mar;56(3):99-103 https://pubmed.ncbi.nlm.nih.gov/16696506/

[4] Ayaz, S. Efe, S.Y. (2008). Potentially harmful traditional practices during pregnancy and postpartum.The European Journal of Contraception and Reproductive Health Care https://www.tandfonline.com/doi/abs/10.1080/1362518080204942 7?journalCode=iejc20 Retrieved on the $1^{\text {st }}$ of October, 2020 @ $10 \mathrm{hrs}$

[5] Baker, P.N.(2006). Obstetrics by Ten Teachers(18 ${ }^{\text {th }}$ ed.). London: Arnold 2006;20-33

[6] Brown, H.L., 2019, Redefining Maternal Deaths. A paradigm shift toward the continuum of well women's health. Contemporary $O B / G Y N$.https://www.contemporaryobgyn.net/view/redefiningpostpartum-care Retrieved on the $30^{\text {th }}$ of September, $2020 @ 14 \mathrm{hrs}$

[7] Cindy-Lee, D. Fung, K. Sophie, G., Gail, R. Sarah, R. Lori, R. (2007). Women's Health (2007) 3(4), 487-502 10.2217/17455057.3.4.487

https://www.researchgate.net/publication/26870235_Traditional_p ostpartum_practices_and_rituals_A_qualitative_systematic_revie w Retrieved on the 30th September, 2020 @ 10hrs

[8] Ensor T, Green C, Quigley P., (2014). Mobilizing communities to improve maternal health: results of an intervention in rural Zambia. Bull World Health Organ. 2014;92(1):51-59. doi: 10.2471/BLT.13.122721. [PMC free article] [PubMed] [CrossRef] [Google Scholar]

[9] Fraser, D.M. Cooper, M.A.(eds.). (2009). Myles Text Book for Midwives(14 ${ }^{\text {th }}$ ed.) ISBN 0443072353. London: Churchill Livingstone

[10] Gölbaşı Z, Eğri G., (2010). Traditional practices to mother care in postpartum period. Cumhuriyet Med J 2010;32:276-82

[11] Hilber, A.M. Hull, T.H. Preston-Whyte, E. Bagnol, B. Smit, J. Wacharasin, C. Widyantoro, N. (2010). A cross cultural study of vaginal practices and sexuality: Implications for sexual health. Social Science \& Medicine 70 (2010) 392-400 https://www.researchgate.net/publication/38083003_A_cross_cult ural_study_of_vaginal_practices_and_sexuality_Implications_for_ sexual_health Retrieved on the $1^{\text {st }}$ of October, 2020@ 20hrs

[12] Hyder, A.A., Morrow, R.H. (2005). Culture, Behaviour, and Health www.jblearning.com

[13] Inhorn, M.C. (2003). Local babies, global science: gender, religion and in vitro fertilization in Egypt. New York, NY: Routledge; pp. 5-6. [Google Scholar]

[14] Jacobs, C. Michelo, C. Moshabela, M. (2018). Implementation of a community-based intervention in the most rural and remote districts of Zambia: a process evaluation of safe motherhood action groups.PubMed Central doi: 10.1186/s13012-018-07661https://www.ncbi.nlm.nih.gov/pmc/articles/PMC5984469/ Retrieved on the $1^{\text {st }}$ of October, 2020 @ 18hrs

[15] Kaewsarn. P., Moyle, W., Creedy, D. (2003). Thai nurses' beliefs about breastfeeding and postpartum practices. Journal of Clinical Nursing, 12, 467-475

[16] Kennedy, V. (2020). Theoretical Perspective on Culture. Socialsci.libre

[17] Khaskheli, M.N., Baloch, S. Sheeba, A. (2013). Risk factors and complications of puerperal sepsis at a tertiary healthcare centre. Pak J Med Sci. 2013;29(4):972-76

[18] Kuzel, A. (1992). Sampling in qualitative inquiry. In: Crabtree, B. and Miller, W., Eds., Doing Qualitative Research. Newbury Park, Sage

[19] Lebrón, A. (2013).What is Culture? Merit Research Journal of Education and Review Vol. 1(6) pp. 126-132, July, 2013https://pdfs.semanticscholar.org/023b/0223f2673be190d6978 e85f4d7fb606125ad.pdf Retrieved on the 1st of October, 2020 @ $10 \mathrm{hrs}$

[20] Lundazi District Health Office Information Management System, 2014-2016 
[21] Maimbolwa, M.C. Yamba, B. Diwan, V. Avirdson, Anna-Berit, Ransjö-Arvidson .(2003). Journal of Advanced Nursing Blackwell Publishing https://onlinelibrary.wiley.com/doi/full/10.1046/j.1365-

2648.2003.02709.x Retrieved on the 1st of October, 2020 @ 13hrs

[22] Mathews, A. (1995). Menstruation issues in Bangladesh. Footsteps. 1995;24:2-3. [Google Scholar]

[23] Mishra, L. (2016). Focus Group Discussion in Qualitative Research TechnoLEARN Vol. 6: No. 1: p. 1-5, June 2016 DOI: 10.5958/2249-5223.2016.00001.2

https://ndpublisher.in/admin/issues/tlV6N1a.pdf Retrieved on the 1st of October, 2020 @ 16hrs

[24] Nahas V., Amasheh N. (1999). Culture care meanings and experiences of postpartum depression among Jordanian Australian women: a transcultural study. J. Transcult. Nurs. 10(1), 37-45

[25] Narayan,K.A. Srinivasa, D.K. Pelto, P.J. Veerammal, S. (2001). Puberty Rituals, Reproductive Knowledge and Health of Adolescent School girls in South India.A sia-Pacific Population Journal, June 2001.2 https://www.oecdilibrary.org/docserver/65d467c6-en.pdF Retrieved on the 1 st October, $2020 @ 22 \mathrm{hrs}$
[26] Ngonzi, J., Tornes, Y.F., Mukasa, P.K. et al., (2016). Puerperal sepsis, the leading cause of maternal deaths at a Tertiary University Teaching Hospital in Uganda. BMC Pregnancy Childbirth 16, 207 https://doi.org/10.1186/s12884-016-0986-9

[27] Ricci, S.S. (2013). Maternity, Newborn, and Women's Health Nursing $\left(3^{\text {rd }}\right.$ ed.) ISBN 1-60831-801-X, Philadephia:Wolters Kluwer Health- Lippincott Williams \&Wilkins

[28] Ritzer, G. (2008). Sociological Theory ( $8^{\text {th }}$ ed.). McGrawHill. New York

[29] Shireen J.J. (1998). Infertility in India-levels, patterns and consequences: priorities for social research. J Fam Welf 44:15-24. [Google Scholar]

[30] Swingler, G.R., Bigrigg, M.A., Hewitt, B.G., McNulty, C.A.M. (1988). Disseminated intravascular coagulation associated with group A streptococcal infection in pregnancy. Lancet; i: 14561457.

[31] World Health Organization, (1995). The Prevention and Management of Puerperal Infections. Report of a Technical Working Group Geneva, 20-22 May 1992 